\title{
Kozmetik Ürünlerin Fototoksik Etkileri: Mekanizması ve Alternatif Test Metotları
}

\author{
Özge Köse, Pınar Erkekoğlu, Suna Sabuncuoğlu, Belma Koçer-Gümüşel
}

\section{ÖZET}

Güneş 1şığ 1 ve fotoreaktif ksenobiyotiklere maruz kalan deride, normal olmayan deri reaksiyonları görülebilir. Fototoksisite, fotoreaktif kimyasal maddeler ve ışığa derinin aynı anda maruz kalması sonucu oluşan yanıtı olarak tanımlanır. Eritem, ödem, deri irritasyonu, kaşıntı gibi çeşitli belirtiler ile kendini gösterir. Bazı organik kimyasal maddelerin moleküler yapılarının UV ışı̆̆ı absorblayan özellikte olması, madde tarafından oluşturulacak fototoksisiteyi indükleyebilir. Bu yapıya sahip ilaç ve kozmetik ürünlerin sayısı gün geçtikçe artmaktadır. Kimyasal maddelerin fototoksik potansiyellerini belirlemek için çeşitli test yöntemi geliştirilmiştir. Özellikle 3R kuralının kabul görmesinden sonra kimyasal maddelerin ve kozmetik ürünlerin potansiyel toksik etkilerinin değerlendirilmesi için, in vivo modellerin yerine birçok alternatif in vitro yöntem geliştirilmiş, valide edilmiş ve düzenleyici kuruluşlar tarafından kabul edilmiştir. 11 Mart 2013 tarihinde Avrupa Birliği'nde hayvanlar üzerinde test edilen her tür kozmetik ve kişisel bakım ürününün satışının yasaklanması ile birlikte kozmetik ürünlerin güvenlilik değerlendirmelerinde alternatif In vitro toksisite testleri kullanılmaya başlanmıştır. Fototoksisite testleri de dahil bu alternatif testler birçok toksisite çalışması için uygundur. Bu derlemede fototoksisitenin mekanizması ile bu toksik etkinin belirlenmesi amacıyla kullanılan alternatif test yöntemleri değerlendirilecektir.

Anahtar Kelimeler: Fototoksisite, Alternatif Yöntem, Kozmetik Ürün, In vitro toksikoloji
Belma Koçer-Gümüşel

Hacettepe Üniversitesi, Eczacilı Fakültesi, F.Toksikoloji Anabilim Dall, Sihhiye Ankara Türkiye

Sorumlu Yazar:

Belma Koçer-Gümüşel

e-mail:belmagumusel@yahoo.com

Submitted / Gönderilme: 19.10.2016 Revised / Düzeltme: 19.11.2016

Accepted / Kabul: 22.11.2016

\section{GİRIş}

İnsanlar da dahil olmak üzere, karada yaşayan tüm canlılar sürekli olarak güneş ışı̆̆ına maruz kalır. Çevresel mikroorganizmalar, kimyasal maddeler, radyasyon ve çok çeşitli alerjenlere karşı bir bariyer görevi teşkil eden deri, güneş ışı̆̆ından en çok etkilenen organdır. Güneş ışığından kaynaklanan yanıklar, eritem, hiperpigmentasyon, fotoyaşlanma ve deri kanseri deriye ilişkin en sık görülen istenmeyen etkilerdir (1). Fototoksisite, tüm ışık kaynaklı doku reaksiyonlarını tanımlamak için kullanılan bir terimdir (2). Fototoksisite, organizmaya uygulanan bir maddeye derinin toksik cevabı olup, topikal veya sistemik olarak kimyasal maddeye maruziyeti takiben ışıkla temas sonrasında akut olarak ortaya çıkar (3). Bu nedenle fototoksisitenin en belirgin klinik belirtileri deri irritasyonu, eritem, ödem, kaşıntı ve deri yanıklarıdır (4). Fotoalerji, belirli bir maddeye duyarlı bireylerde immün sistemin aktivasyonu sonucunda oluşan bir alerjik reaksiyondur ve tip IV gecikmiş hipersensitivite yanıtıdır. Reaksiyon için alerjen maddenin 
Tablo 1. Fotoalerjen ve fotoaktif maddelerin neden oldukları fototoksik ve fotoalerjik reaksiyonlarının ana özellikleri

\begin{tabular}{lll}
\hline & Fototoksik reaksiyonlar & Fotoalerjik reaksiyonlar \\
\hline İnsidans & Yüksek & Düşük \\
Duyarlanma & Yok & Var \\
Klinik Görünüm & Güneş yanığı benzeri reaksiyonlar, eritem, ödem & Egzama, kaşıntı \\
Başlangıç Semptomları & Fotomaruziyet sonrası dakika-saat içerisinde & Fotomaruziyet sonrası 24-48 saat içerisinde \\
Patofizyoloji & Doğrudan hücre hasarı, DNA hasarı, reaktif oksijen & Tip IV hipersensitivite \\
Histoloji & bileşiklerinin (ROB) oluşumu, inflamasyon & Sponjiyotik dermatit, dermal lenfohistiyositik infiltrasyon \\
Çapraz reaksiyon & Epidermal nekroz, dermal ödem & Siklıkla var \\
Teşhis & Yok & Klinik ve foto-yama testler \\
\hline
\end{tabular}

minimal konsantrasyonu yeterli olup, genellikle tekrarlayan maruziyetler sonrasında reaksiyon gelişir $(5,6)$.

Fototoksisite ve fotoalerjik reaksiyonlar arasındaki klinik ayrım oldukça zordur ve her iki durum da eş zamanlı gerçekleşebilir. Aşağıdaki tabloda fotoalerjen ve fotoaktif maddelerin neden oldukları fotosensitivite reaksiyonlarının ana özellikleri verilmiştir (Tablo 1) (7).

\section{FOTOTOKSIKK KİMYASAL MADDELER}

Bir kimyasal maddenin fototoksisite ve/veya fotoalerji oluşturmasında aşağıda sıralanan özelliklere sahip olması önemlidir:

- Doğal güneş 1şı ̆̆ 1 (290-700 nm) aralığında 1şı̆̆ı absorplaması

- UV-görünür ışı̆̆ın absorbsiyonu sonrası reaktif türler oluşturması

- Işığa maruz kalan dokularda (örneğin deri, göz) yeterince dağılabilmesi

Kimyasal maddeler bu koşullardan biri veya birkaçına sahip değil ise, bileşiğin genellikle doğrudan fototoksik bir reaksiyona yol açabileceğinden endişe edilmemelidir. Ancak, aynı zamanda dolaylı mekanizmalar ile de deride duyarlılık oluşabilmektedir (8).

İlaçlar gibi kimyasal maddelerin geniş bir spektrumu, benzen ya da heterosiklik halkalar gibi UV ışınları absorbe edebilen yapilara sahip olmaları nedeniyle fototoksisite potansiyelleri olduğu düşünülmektedir (911). Bu tip ilaçlara örnek olarak antibiyotikler (kinolonlar, tetrasikilinler, sulfonamidler) (12), antihistaminikler, antimalaryal ilaçlar (kinin, klorokin), antikanser ajanlar (5-florourasil, vinblastin, vemurafenib, dakarbazin) (13), kardiyovasküler sistem ilaçları (aminodaron, nifedipin, kinidin, diltiazem), diüretikler (furosemid, tiyazidler), antidiabetikler (sulfonilüre), non-steroidal anti-inflamatuvar ilaçlar (naproksen, piroksikam, diklofenak, selekoksib (14), antifibrotik ilaçlar (piferindon) $(15,16)$ ve psikiyatrik ilaçlar verilebilir (fenotiyazinler, trisiklik antidepresanlar).

UV radyasyonu ya da yapay ışı kaynakları birçok ilaçta ışığa bağlı bozulmaya (photodecomposition) neden olabilir. Fotostabilite, ilaçların doğru raf ömrünün belirlenmesi ve sağlanmasında büyük bir engel teşkil etmektedir. Işığa bağlı bozulma sırasında, ışıkla uyarılmış (foto-eksite) ilaç molekülleri toksik bileşiklere dönüşebilmekte veya deri hücrelerinde doğrudan toksisiteye neden olan ROB oluşturabilmektedir (9).

Deri, kozmetik ürünlere ve beraberinde UV ve görünür ışığa (290-700 nm) maruz kalabilir. Bazı kozmetik ürünlerinin, fototoksik deri reaksiyonlarını uyardığı bilinmektedir (17). Bu nedenle ürünlerin güvenlilik değerlendirmesinde bileşenlerinin foto-güvenliliği önemli bir unsur haline gelmiştir (18, 19) . Foto-güvenlilik değerlendirmelerinde; fototoksisite (fotoirritasyon) ve fotoalerjinin belirlenmesi temel amaçtır (20).

\section{FOTOTOKSİSITTENIN MEKANIZMASI}

Güneş 1şığı, değişik yoğunlukta enerji dalgaları yaymaktadır (21). Deniz seviyesinde güneş ışığı 290-3000 nm dalga boylarındaki 1şımalardan oluşur. 290 nm’den daha kısa dalga boyundaki ışınmalar ozon tabakası ve stratosferdeki moleküler oksijen tarafından selektif olarak absorbe edildiği için deniz seviyesine ulaşamaz (22). Dünya yüzeyine ulaşan güneş 1şını;

1. UV bölgesi (290-400 nin)

2. Görünür 1şı1k (400-760 nın)

3. infrared ışıma (760 nın'den daha uzun dalga boylu) olarak üç alt gruba olarak ayrılır(8). 
Penetrasyonun enerjisi ve miktarı da gelen ıșığın dalga boyuna bağlı olarak değişir. UVA ve UVB gibi güneş ışığındaki kısa dalga boylu ışımalar fototoksisiteden sorumludur. UVgörünür 1şık ile oluşan fototoksisite, güneş ışı̆̆ 1 ve fotoreaktif kimyasal maddelerin ortak katkısı ile meydana gelir (21). Aralarında dalga boyu en uzun olan, UV'nin \%90-92'sini oluşturan UVA (320-400nm), derinin alt tabakası dermise kadar geçer. Reaksiyonların şiddeti, deride bulunan melanin pigmenti miktarına ve UVA ışımanın dozuna bağlıdır. UVB (290-320 nm), güneş yanı̆̆ından asıl sorumlu olan ve deride melanin pigment sentezini stimüle eden en etkili banttır. Deride serbest radikal oluşumunu arttırır, oksidatif reaksiyonlarda hücre ve dokuların yıkılması sonucu ağrı ve inflamasyon ortaya çıkar. Deri kanseri ve foto-yaşlanma şeklinde etkileri ise, kronik maruziyetin bir sonucu olarak ortaya çıkmaktadır $(22,23)$.

Fototoksik ve fotoalerjik reaksiyonlardan genellikle UVB sorumlu değildir. İlaçlara bağlı kutanöz fotosensitizasyon reaksiyonlarından asıl sorumlu olan UVA'dır. Bu nedenle, hem UVA hem de UVB'nin akut ve gecikmiş zararlı etkilerine karşı mutlaka korunma önlemleri alınmalıdır (22).

Enerji, hedef molekülün temel düzeyden uyarılmış hale geçmesiiçin hedef moleküliçindeki elektronları uyarmaktadır. Her bir kromofor benzersiz bir absorbsiyon yelpazesine sahiptir. Uyarılmış moleküller birkaç mikrosaniye içerisinde temel hale döner. Temel hale dönen bu moleküller, 1şı ya da 1 sı yayabilir veya fotokimyasal reaksiyonlara uğrayabilir. Uyarılmış haldeki kromofor oksijene enerjisini devredebilir. ROB singlet oksijen, hidrojen peroksit, süperoksit anyonu ve hidroksil radikalleri içeren küçük moleküllerdir ve hücre membran ve organellerdeki doymamış lipitleri, aromatik aminoasitleri, DNA ve RNA'da bulunan pirimidin bazlarını okside edebilir. Okside ürünler çoklu inflamatuvar mediyatörlerin salımını tetikleyebilmekte ve bu nedenle inflamasyon ve eriteme neden olabilmektedir (24).

Fotoaktif kimyasal maddeler foton ve enerji absorblar ve böylelikle kimyasal maddelerde moleküler değişiklikler meydana gelebilir ya da ROB üretimiyle hedef organlarda toksisite gelişebilir. Fotokimyasal reaksiyonların ara ürünleri doğrudan sitotoksisiteye neden olan radikalleri içerir. Fotouyarılmış moleküller, komşu oksijen molekülüne enerji transfer edebilir ve sitotoksisitesi yüksek olan singlet oksijen formuna dönüștürebilir (25).

Fototoksik reaksiyonlar, endojen veya ekzojen kromoforların UV radyasyon ile etkileşimi sonucu oluşan, immünolojik olmayan reaksiyonlardır. Fototoksik kimyasal maddenin varlığında, UV radyasyona veya görünür ışığa maruziyet sonrası oluşan hücresel hasarın sonucu olarak fototoksisite meydana gelir. Fototoksik ajanlar endojen olabildiği gibi ekzojen de olabilir (26). Fototoksik reaksiyonlar UV radyasyonu, kromofor veya fotosensitizana maruziyet ile görülebilir ve reaksiyon ışık fotonu absorbsiyonunun takibinde başlar. Bazı fototoksik maddeler de kromozomal hasara neden olabilir. Mutajenik ve immunosüpresif özellikleri nedeniyle reaksiyon karsinojenez gelişimiyle sonuçlanabilir (27).

\section{KOZMETIK ÜRÜNLERDE FOTOTOKSİSITTENIN BELIRLENMESINDE KULLANILAN TESTLER VE ALTERNATIF YÖNTEMLER}

Russell ve Burch tarafindan 1959 yilında yayınlanan 3R kuralının (hayvan sayısını azaltma, yerine koyma, iyileştirme) uygulamaya konmasıyla birlikte $(28,29)$, in vivo yöntemler yerine ex vivo ve in vitro alternatif yöntemler geliştirilmeye başlanmıştır (28). 3R prensibinin uygulanmasının ardından in vivo foto-güvenlilik testleri son yllarda kozmetik endüstrisinde geçerliliğini yitirmiş testler haline gelmiştir. 1223/2009 sayll Avrupa Birliği Kozmetik Tüzügü’ne göre 2004 yılından itibaren bitmiş kozmetik ürünlerin, 2009 yllından itibaren ise kozmetik ürün bileşenlerinin hayvan deneylerinde test edilmesi yasaklanmıştır (30). Hayvanlar üzerinde denenen her tür kozmetik ve kişisel bakım ürününün Avrupa Birliği’nde satışı 11 Mart 2013 itibariyle yasaklanmıştır. Bu yasak, Avrupa Birliğỉnin dışında yer alan ülkelerden ithal edilen ürünler için de geçerlidir (31).

Bilimsel amaçla deneylerde kullanılan hayvanların korunması için yayınlanan 2010/63/EU direktifine göre, sonuca ulaşmada kullanılacak başka yöntem veya test stratejileri varsa, deneylerde canlı hayvan kullanılmamasının gerektiği belirtilmiştir (32). Diğer taraftan, kozmetik direktifi ve yönetmeliğine göre, hayvan testlerine alternatif yöntemlerin olmadığı durumlarda bile test ve pazarlama yasakları uygulanmaktadır.

Çeşitli in vitro foto-güvenlilik değerlendirme testleri in vivo deneylerin yerine alternatif test yöntemleri olarak kullanıma girmiştir (33). Ancak, güvenilir ve kapsamlı bir hayvan kullanılmayan foto-güvenlilik tarama stratejilerinde eksiklik bulunmaktadır ve konu ile ilgili yeni yöntemlere halen gereksinim duyulmaktadır (34).

Kozmetikler ve farmasötik formülasyonların içeriğinde bulunan birçok kimyasal maddeye günlük hayatta giderek artan düzeylerde maruz kalınmaktadır. Bu kimyasal maddelerin fototoksisite potansiyellerinin belirlenmesinde 
in silico (35), in chemico (19), in vitro ve in vivo analiz yöntemleri kullanılmaktadır. Örneğin, ROB oluşumunun tayini gibi kimyasal analizler (36), 3T3 Nötral Kırmızı Alım Testi (3T3-NRU), 3D epidermis modellerin uygulandığ 1 in vitro analizler, domuz, fare veya sıçanların kullanıldığı in vivo deneyler rutin olarak kullanılmaktadır (37).

\section{In vivo Fototoksisite Testleri}

Fototoksik deri reaksiyonlarının belirlenmesinde; in vivo fototoksisite ve fotoalerji testleri kobay, tavşan, sıçan ve fare kullanılarak gerçekleştirilmektedir. Ancak etik açıdan düşünüldüğünde bu tür testlerin laboratuvar hayvanları üzerinde yapılması, hayvanlara önemli derecede rahatsızlık ve ac1 verme potansiyeline sahiptir.

Fare, kobay, domuz gibi laboratuvar hayvanları insanlarda oluşabilecek fototoksisitenin tespit edilmesinde kullanılan modellerdir. Hayvanlar topikal ya da sistemik olarak test maddesine ve uygun dozlarda UVA'ya maruz birakılır (38). Eritem ve ödem oluşumu 0-4 arasında skorlanır ve 72 saatlik gözlem boyunca maksimum skorun hayvan başına ortalaması alınır. Fototoksisite indeksi aşağıdaki denklem ile elde edilir:

UVA 1şınıyla oluşturulmuş irritasyon indeksi - ışınlama olmayan irritasyon indeksi (39)

0.6 indeks değeri üzerindeki değerler potansiyel fototoksisiteyi gösterir.

Bir diğer yöntem ise, fare testlerinde kulak kalınlığı ödeminin belirlenmesi prensibine dayanarak ölçülmektedir. $\mathrm{Bu}$ in vivo testler bahsedildiği gibi hayvan refahı ve etiksel açıdan pek çok sorun teşkil etmektedir. Hayvan kullanılmayan fototoksisite testleri bu sorunların üstesinden gelmek açısından oldukça önem taşımaktadır $(40,41)$.

\section{In vitro Fototoksisite Testleri}

\section{$3 T 3$ Nötral Kırmızısı Gerialım Testi}

Fototoksisitenin belirlenmesi kullanılan 3T3 nötral kırmızısı gerialım testini ayrıntıları (NRU 3T3 Neutral red uptake assay) OECD TG 432 (Test No. 432: In vitro 3T3 NRU Phototoxicity Test) kılavuzunda verilmiştir. Bu yöntem, ışı̆̆a maruziyet sonrası uyarılmış kimyasal maddelerin potansiyel fototoksisitesini tanımlamak için uygulanır. Bu test, ışı̆̆ın varlığında ve yokluğunda kimyasal maddeye maruz kalmış hücrelerin canlılığındaki azalmaya göre foto-sitotoksisiteyi değerlendirir. Canlı hücreler, zayıf katyonik bir boya olan nötral kırmızı boyasını hücre membranlarından penetrasyon yolu ile intraselüler ortama alarak lizozomlarında biriktirir (3). Bu testteki sitotoksisite, hücrelerin test maddesine ve ışınlamaya maruziyetini takiben, nötral kırmızısı boyasının hücreler tarafından alımının madde konsantrasyona bağlı olarak azalması şeklinde ifade edilir (42).

Fare fibroblastı Balb/c 3T3 hücreleri, kimyasal maddeye maruz bırakıldıktan sonra UVA/görünür 1şı̆̆a $5 \mathrm{~J} / \mathrm{cm}^{2} \mathrm{UVA}$ dozunda maruz bırakılır (+UV deneyi), diğer plaka ise karanlıkta saklanır (-UV deneyi). Her iki plakta da maddeyi içeren hücre kültürü medyumu taze medyumla değiştirilir ve takiben 24 saatlik inkübasyon sonrasında NRU testi ile hücre canlılığı değerlendirilir. Hücre canlılığı, kimyasal maddeye maruz kalmamış negatif kontrollerin yüzdesi olarak ifade edilir. Test edilen kimyasal maddelerin her konsantrasyonu için hücre canlılığı hesaplanır. Test edilen maddenin fototoksisite potansiyelinin değerlendirilmesinde, radyasyon varlığında $(U V+)$ ve yokluğunda (UV-) dozcevap eğrisi kullanılır. "Foto-irritasyon Faktörü (PIF)" veya “Ortalama Foto Etkisi (MPE)" hesaplanır (43). PIF değeri, radyasyon yokluğunda inhibitör konsantrasyon 50 ( $\mathrm{IC}_{50}$ : hücre canlılığını \%50 oranında düşüren konsantrasyon) değerinin, radyasyon varlığında $\mathrm{IC}_{50}$ değerine oranıdır (Şekil 1). $\mathrm{IC}_{50}$ 'nin elde edilemediği durumlarda MPE değeri OECD 432 kılavuzunda belirtildiği gibi hesaplanır (21).

$$
P I F=\frac{I C_{50}(U V-)}{I C_{50}(U V+)}
$$

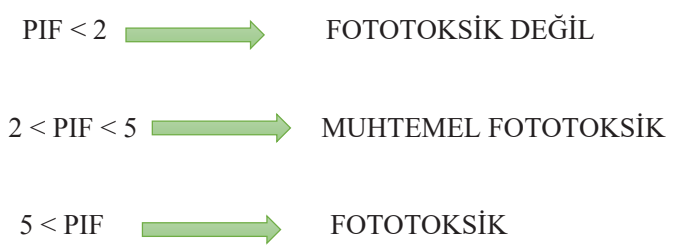

Şekil 1. PIF hesabı ve sonuçlarının değerlendirilmesi

$\mathrm{Bu}$ testin uygulanmasında bazı sinırlandırmalar söz konusudur:

- Foto(sito)toksisite dışında diğer advers etkiler tahmin edilemez. Kimyasal ve ışı̆̆ın kombine maruziyeti sonrasında fotogenotoksisite, fotoalerji ya da fotokarsinojenite ortaya çıkabilmektedir.

- 3T3 fototoksisite testi yalnızca tehlikenin tanımlanmasını kapsar; fototoksik etki gücünün değerlendirilmesi için kesinlik sağlamaz (21). Bununla birlikte, son yıllarda suda çözünür bileşiklerin fototoksisitesinin belirlenmesinde en uygun In vitro test olarak kabul edilmektedir. 
Alternatif Yöntemlerin Validasyonu Avrupa Merkezi (The European Centre for the Validation of Alternative MethodsECVAM) tarafından yürütülen validasyon çalışmalarında bu testin, \%93 hassaslikta ve \%84 özgünlükte olduğu; ancak ilaçlar için daha düşük özgünlüğünün bulunduğu belirtilmiştir. Eğer test sonucunda bir kimyasal madde için negatif sonuç alınmışsa, bu bileşiğin insanlarda fototoksik olma olasılığı çok düşük kabul edilir. Ancak, bu testte elde edilen pozitif sonuçlar klinikte kesin bir fototoksik risk göstergesi değildir; söz konusu sonuç hastanın takibinin değerlendirilmesinde kullanılmaktadır (8).

\section{Eritrosit hemoliz testi}

Hücre membranları, fotokimyasal olarak üretilen ROB ve diğer radikallerin etkilerine karşı hedef konumundadır. UVA-kaynaklı eritrosit hasarları ve bunun sonucunda oluşan hemoliz (fotohemoliz) test maddelerinin fototoksik potansiyelini değerlendirmek için kullanılır (44). Bu testte, koyun alyuvar hücreleri (SRBC) kimyasal maddeler ile inkübe edilir ve $20 \mathrm{~J} / \mathrm{cm}^{2}$ UVA ile ışınlanır. Işınlama sonrasında, SRBC'ler 2 saat oda sıcaklığında karanlık ortamda inkübe edilir ve daha sonra 1 saat süre ile $37^{\circ} \mathrm{C}$ ye alınır. Takiben, Drabkin reaktifi ile $540 \mathrm{~nm}$ de UV absorbans ölçümü yapılır. Fototoksisite derecesi, SRBC'lerden hemoglobinin serbest bırakılmasına göre değerlendirilir. Fotohemolitik aktivite aşağıdaki denklem ile belirlenir (45).

$$
\text { Fotohemolitik aktivite }(\%)=\frac{A D E-A D}{C} \times 100
$$

ADE: ilaç çözeltisinin eritrositler ile maruziyetinin optik dansitesi AD: ilaç çözeltisinin eritrositsiz maruziyetinin optik dansitesi C: $100 \%$ hemolitik kontrol çözeltisinin optik dansitesi

Siprofloksazin, norfloksazin ve enoksazin gibi fototoksik ilaçlar, $100 \mu \mathrm{g} / \mathrm{mL}$ 'nin üzerindeki dozlarda önemli ölçüde fotohemolitik aktiviteyi arttırır. Yirmidört farklı kimyasal maddede (8 koku, 5 UV absorbanı, 4 ilaç, 4 antimikrobiyal ve 3 boya) yapılan analizlerde testin duyarlılığı, özgünlüğü ve doğruluğu In vivo testler ile karşılaştırıldığında sırasıyla $\% 67, \% 73$ ve \%73'dür. Bu testin daha az kullanılması düşük duyarlılık oranına sahip olması ile açıklanabilir (46).

\section{In vitro insan $3 D$ epidermis modeli}

In vitro hücre tabanlı yöntemlerin sinırlamaları nedeniyle normal insan keratinositlerinden oluşan "3 boyutlu (3D)
Yeniden Yapılandırılmış İnsan Epidermis Modelleri (RhE)" geliştirilmiştir (47). Bu modeller genel olarak, in vivo epidermis yapısına benzer özelliklere sahip olup, çok sayıdaki maddeye karşı engel teşkil eden Stratum corneum tabakasını içerir. Bu modeller, topikal olarak uygulanan saf kimyasal maddelerin ve son klinik formülasyonların test edilmesine olanak sağlamaktadır. EpiDerm, SkinEthic ve EpiSkin 3D doku modelleri in vitro fototoksisite testlerinde kullanılmaktadır (47).

EpiSkin modeli normal insan epidermisine fosfolipit ve seramit yapıları yönüyle oldukça benzerdir. Lanosterol içermesi bir diğer benzer özelliklerindendir. Ancak, EpiSkin modelindeki bazı hücrelerin organizasyonu normal insan epidermisi ile farklılık gösterir. Bazal hücreler kübik şekilde olup, üst hücre tabakaları nispeten düz bir yapıya sahiptir. Mevcut olan keratohiyalin ve granüler hücrelerin ise şekilleri nispeten düzensizdir (48-50).

Stratum corneum, Stratum granulosum, Stratum spinosum gibi insan epidermisin en önemli yapılarının SkinEthic modelinde bulunması, bu modelin insan epidermisine oldukça yakın bir model olduğunu kanıtlar niteliktedir (51). SkinEthic modelin insan dokusu ile benzer bir yönü ise lipit kompozisyonları olarak nitelendirilir (49).

EpiDerm modeli "normal, çok tabakalı, insandan türetilmiş epidermis keratinositleri" olarak İlk olarak 1994 yılında Cannon ve ark. tarafından tanımlanmıştır (52). Epidermiste bulunan Stratum corneum, Stratum granulosum, Stratum spinosum tabakaları bu modelde de yer almaktadır. Normal epidermal tabakada bulunan ana lipit sinıfları da bu modelde bulunmaktadır. Keratohiyalin granülleri ise yıldız şeklindedir $(48,49)$. Bu modelde glukosilseramidler yüksek miktardadır (49).

Genel bir değerlendirmeyle, SkinEthic, EpiDerm ve EpiSkin modellerinin insan dokusunu taklit etmek üzere tasarlanan modellerdir. Bu modellerin fototoksisite testleri dahil olmak üzere birçok toksisite çalışmaları için uygun modeller olduğu belirtilmiştir (53).

$\mathrm{Bu} 3 \mathrm{D}$ modellerin kullanıldığı yöntemin prensibi temel olarak 3T3 NRU test prensibine benzer olup, UV/görünür ışınlamanın olduğu ve olmadığı durumlarda doku canlılı̆̆ındaki farklılıkların değerlendirilmesine dayanır. Test maddesi doğrudan doku yüzeyine belirli hacimlerde uygulanır ve gece boyu inkübe edilir. Bir sonraki gün doku yüzeyi yıkanarak 60 dakika $6 \mathrm{~J} / \mathrm{cm}^{2}$ UVA'ya solar simülatörde maruz birakılır. Radyasyon uygulaması sonrasinda dokular tekrar yıkanarak taze besi yeri içerisinde alınır ve üçüncü gün bir tetrazolyum tuzu olan 
3-(4,5-dimetiltiyazol-2-il)-2,5-difeniltetrazolyum bromür (MTT) ile inkübe edilerek mitokondriyal dehidrojenaz aktivitesinn ölçülmesi ile hücre canlılı̆̆ını kolorimetrik olarak belirlenir. Fototoksik potansiyel, sitotoksisitesinin \%30 ve üzeri artış göstermesi olarak değerlendirilir (54).

RhE modelleri 3T3 NRU testine göre bazı avantajlara sahiptir. In vivo insan derisine benzer deri bariyerinin varlığ 1 , hücrelerdeki metabolik yeterlilik, bariyer özellikleri, doku kalitesinin tam olarak kontrol edilebilmesi, kolay uygulama ve sınırlı çözünürlüğü olan maddeler için kaygıların olmaması bu yöntemlerin üstünlükleri olarak değerlendirilmektedir (54). RhE modellerinin, topikal olarak uygulanan kimyasal maddelerin fototoksik tehlikelerinin belirlenmesinde güvenilir bir şekilde kullanılabileceği ileri sürülmektedir. $\mathrm{Bu}$ doku modelleri 3T3 NRU testinin alternatifi olarak veya 3T3 NRU testinin hatalı pozitif sonuçlarının sayısını azaltmak amacıyla pozitif sonuçların doğrulanması için bir ara kademe test olarak kullanılabilir (55).

Ön validasyonu yapılmış EpiDerm fototoksisite testinin fototoksisite çalışmaları için güvenirliliğinin belirlenmesi amacıyla ECVAM destekli fizibilite çalışması gerçekleştirilmiştir. 3T3 NRU testinde pozitif sonuç veren iki örnek ve in vivo testte negatif sonuç veren bir örnek RhE model üzerinde denenmiş ve doğru sonuçlar elde edilmiştir (55). Örneğin, bergamot yağı topikal olarak uygulanan bir bitkisel bir üründür. Farklı bergamot yağları farklı miktarlarda furokumarin içermektedir. Ayrıca, analizlerde kullanılan çözücüler de sonuçları etkilemektedir. Örneğin, 3T3 NRU testinde bergamot yağı PBS içerisinde fototoksik olarak tanımlanırken, çözücü olarak \%1 etanol veya \%1 DMSO içeren PBS kullanılması durumunda fototoksik olmayan madde olarak tanımlanmıştır (56). EpiDerm 3D fototoksisite testi ile değişik tipteki bergamot yağlarının fototoksik potansiyellerindeki farklılıklar ortaya konmuştur. Elde edilen sonuçlar, insan foto-yama testleri ile de korelasyon göstermiştir (56). Bu sonuçlara göre, yeniden yapılandırılmış insan doku modellerinin topikal olarak uygulanan maddelerin foto-güvenliliğinin tahmininde uygun modeller olduğu belirtilmiştir.

\section{Fototoksisitenin değerlendirilmesinde in chemico test yöntemi}

Herhangi bir hücre hattının kullanılmadığı in chemico yöntem ile de fototoksisite değerlendirilebilir. Test maddesinin fotostabilitesi ve ışığı absorblanmasından elde edilen veriler analiz edilerek fototoksisite hakkında tahminlerde bulunulabilir (57). Işık ile uyarılma sırasında ve fotoreaksiyon sonrasında ROB oluşumu ile bir kimyasal maddenin fototoksik potansiyeli in chemico olarak değerlendirilebilir (58). Singlet oksijen p-nitrozodimetilanilin ile tespit edilirken, peroksit üretimi "Nitro Blue Tetrazolyum Testi (NBT- Formazan ekstraksiyonu)" ile belirlenir (36). Bu yöntem kozmetik ürünler için $\% 90$ hassaslıkta ve $\% 76,9$ özgünlüktedir; diğer kimyasal maddeler için ise sırasıyla $\% 100$ hassaslıkta ve \%75 özgünlükte olduğu belirlenmiştir.

\section{SONUÇ}

Günümüzde Avrupa'da, kozmetik ürünlerin toksisite profillerinin belirlenmesinde hayvan testlerinin yerini valide in vitro yöntemler almıştır (59). Avrupa Birliği Kozmetik Direktifine göre 11 Mart 2013 tarihinde, kozmetik ürünlerin güvenlilik değerlendirmelerinin deney hayvanları kullanılarak yapılması yasaklanmıştır. $\mathrm{Bu}$ pazarlama yasağının sürdürülmesi, alternatif yöntemlerin geliştirilmesi ve valide edilmesi, uluslararası işbirliğinin ayrılmaz bir parçası olmuştur. Pazarlama yasağı, insan güvenlik değerlendirmesine ilişkin köklü bir değişiklik getirmiştir (32).

Fotoyaşlanma, hiper-pigmentasyon, deri kanserleri gibi güneş 1şığı ile ilişkili sağlık sorunlarının sıklığı ve şiddeti giderek artmaktadır. Güneş ışığı ve kozmetik ürün gibi kimyasal maddelerin kombine etkileri göz önüne alındığında, fototoksisitenin mekanizmasının açığa çıkarılmasına ilişkin çalışmalarının desteklenmesi ve yeni yöntemlerin geliştirilmesi gerektiği sonucuna ulaşılmaktadır. Güncel in vitro test yöntemlerinin özellikle fototoksik potansiyel ile ilgili bilgi sağlama ve metabolik kapasite eksikliği gibi birçok noktada iyileștirilmeye ihtiyacı bulunmaktadır.

Avrupa Birliği’nin yasağından önce güvenlilik değerlendirmeleri in vivo şartlarda yapılsa da, yeni kozmetik ürünlerin toksikolojik çalışmaları in vitro test yönemleri kullanılarak tekrarlanmalıdır. Yakın gelecekte in vitro yöntemlerin kullanımında artış olacağına inanılmaktadır. Halen uygulanmakta olan valide yöntemler mevcut olsa da, daha ileri çalı̧̧malar için yeni yöntemlerin geliştirilmesi, geçerliliğinin ve validasyonunun sağlanması gerekmektedir(60). 
Phototoxic Effect of Cosmetic Products: Its Mechanism And Alternative Test Methods

\section{ABSTRACT}

Abnormal skin reactions may be observed in the skin subject to sunlight and photoreactive xenobiotics. Phototoxicity can be defined as the response to the combined exposure of the skin to photoreactive xenobiotics and light. Phototoxicity occurs with symptoms like erythema, edema, skin irritation and itching. The UV-absorbing properties of various organic chemicals, can lead to induction of phototoxicity by this substances. Number of drugs and cosmetics, which have such properties, are increasing from day to day. Several test methods were developed to determine the phototoxic potential of chemical substances. Particularly after the acceptance of $3 \mathrm{R}$ principle, many alternative methods were developed, validated and accepted by the regulatory authorities, for the evaluation of the potential toxic effects of the chemicals. On March 11, 2013, the commercial sale of all cosmetics and personal care products, which were tested on animals, was banned in the European Union and since then the safety evaluation of the cosmetics is being conducted by alternative In vitro toxicity tests. These tests, including tests for phototoxicity, are suitable for many toxicity studies. This review will focus the mechanisms of phototoxicity and the alternative test methods used for the detection of this particular toxic effect.

Keywords: Phototoxicity, alternative methods, cosmetic products, In vitro toxicology

\section{KAYNAKLAR}

1. Freeman AK, Gordon M. Dermatologic diseases and problems. In: Geriatric Medicine (4th edition). Springer, New York. 2006, pp. 869-881.

2. Kim K, Park H, Lim KM. Phototoxicity: Its Mechanism and Animal Alternative Test Methods. Toxicol Res 2015;31:97104. Review. Erratum in: Toxicol Res 2015; 31:321.

3. Organization for Economic Cooperation and Development (OECD) Test No. 432: In vitro 3T3 NRU Phototoxicity Test. OECD, Paris: OECD Publishing. No. 432, Paris 2004.

4. Lugovic L, Situm M, Ozanic-Bulic S, Sjerobabski-Masnec I. Phototoxic and photoallergic skin reactions. Coll Antropol 2007;1: 63-7.

5. Allen JE. Drug-induced photosensitivity. Clin Pharm 1993;12:580-7.

6. Lim HW. Abnormal responses to ultraviolet radiation: photosensitivity induced by exogenous agents. In: Fitzpatrick's Dermatology in General Medicine. Editors: Wolff K, Goldsmith LA, Katz SI. McGraw-Hill Company, New York. 2007, pp.1589-2820.

7. Maibach H, Honari G. Applied Dermatotoxicology, Clinical Aspects. Elsevier. 2014, pp.41-56.

8. International Conference on Harmonization of Technical Requirements for Registration of Pharmaceuticals for Human Use (ICH), ICH S10 Photosafety Evaluation of Pharmaceuticals Guidance for Industry U.S. Department of Health and Human Services Food and Drug Administration Center for Drug Evaluation and Research (CDER) Center for Biologics Evaluation and Research (CBER), 2015.

9. Tønnesen $\mathrm{HH}$. Formulation and stability testing of photolabile drugs. Int J Pharm 2001; 225:1-14.

10. Gonçalo M. Phototoxic and photoallergic reactions. In: Contact Dermatitis. Springer. 2011, pp.361-376.

11. Ferguson J. Photosensitivity due to drugs. Photodermatol Photoimmunol Photomed 2002;18 :262-9.

12. Adachi T, Satou Y, Satou H, Shibata H, Miwa S, Iwase Y, Yamamoto T, Nishida A, Masutomi N. Assessment of 8-methosypsoralen, lomefloxacin, sparfloxacin, and pirfenidone phototoxicity in Long-Evans rats. Int J Toxicol 2015;34:16-23.

13. Boudon SM, Plappert-Helbig U, Odermatt A, Bauer D. Characterization of vemurafenib phototoxicity in a mouse model. Toxicol Sci 2014;137:259-67.

14. Yazici AC, Baz K, İkizoglu G, Kokturk A, Uzumlu H, Tataroglu C. Celecoxib induced photoallergic drug eruption. Int J Dermatol 2004;43:459-61.

15. Onoue S, Seto Y, Kato M, Aoki Y, Kojo Y, Yamada S. Inhalable powder formulation of pirfenidone with reduced phototoxic risk for treatment of pulmonary fibrosis. Pharm Res 2013;30:1586-96.

16. Seto $\mathrm{Y}$, Inoue R, Kato M, Yamada S, Onoue S. Photosafety assessments on pirfenidone: photochemical, photobiological, and pharmacokinetic characterization. J Photochem Photobiol B 2013;120:44-51.

17. Moore DE. Drug-induced cutaneous photosensitivity: incidence, mechanism, prevention and management. Drug Saf 2002;25:345-72.

18. Epistein JH. Phototoxicity and photoallergy in man. J Am Acad Dermatol 1983;8: 141-7.

19. Onoue S, Tsuda Y. Analytical studies on the prediction of photosensitive/ phototoxic potential of pharmaceutical substanes. Pharm Res 2006:23;156-64.

20. International Conference on Harmonization of Technical Requirements for Registration of Pharmaceuticals for Human Use (ICH), ICH Guideline S10 Guidance on Photosafety Evaluation of Pharmaceuticals, 2014.

21. Kyuri K, Hyeonji P, Kyung-Min L. Phototoxicity: Its Mechanism and Animal Alternative Test Methods Toxicol Res 2015;31: 97-104.

22. Pathak MA, Joshi PC. The nature and molecular basis of cutaneous photosensitivity reactions to psoralens and coal tar. J Invest Dermatol 1983;80:66-74.

23. Roelandts R. Photodermatology over the past 125 years. $\mathrm{Br} \mathrm{J}$ Dermatol 2014;171:926-8.

24. Kochevar IE, Taylor CR, Krutmann J. Fundamentals of cutaneous photobiology and photoimmunology. In: Fitzpatrick's Dermatology in General Medicine ( $8^{\text {th }}$ ed.). 
Editors: Goldsmith LA, Katz SI, Gilchrest BA. McGraw-Hill Professional, USA. 2012.

25. Chignell CF, Motten AG, Buettner GR, Photoinduced free radicals from chiorpromazine and related phenothiazines: Relationship to phenothiazine-induced photosensitization. Environ Health Perspect 1985;64:103-10.

26. Mang R, Stege H, Krutmann J. Mechanisms of phototoxic and photoallergic reactions. In: Contact Dermatitis $\left(5^{\text {th }} \mathrm{ed}\right)$. Editors: Johansen JD, Frosch PJ, Lepoittevin JP. Springer, Berlin. 2011, pp.155-163.

27. Poiger T, Buser HR, Muller M. Photodegradation of the pharmaceutical drug diclofenac in a lake: Pathway, field measurements, and mathematical modeling. Environ Toxicol Chem 2001;20: 256-63.

28. Stephens ML, Mak NS. Reducing, Refining and Replacing the Use of Animals in Toxicity Testing. In: History of the 3Rs in toxicity testing: From Russell and Burch to 21st century toxicology. Editors: Allen D, Walters M. RSC Publishing, Cambridge, UK. 2013, pp.1-39.

29. Russell WMS, Burch RL, Hume CW. The Principles of Humane Experimental Technique. Methuen, London, UK. 1959.

30. European Commision (EC), Regulation (Ec) No 1223/2009 of The European Parliament And Of The Council of 30 November 2009 on Cosmetic Products, Official Journal of the European Union, 2009.

31. European Commision (EC), Communication from the commission to the European Parliament and the councilon the animal testing and marketing ban and on the state of play in relation to alternative methods in the field of cosmetics, Official Journal of the European Union, 2013.

32. European Commision (EC), Directive 2010/63/EU of the European Parliament and of the council of 22 September 2010 on the protection of animals used for scientific purposes. Official Journal of the European Union L, 2010;276:33-79.

33. Seto Y, Hosoi K, Takagi H, Nakamura K, Kojima H, Yamada $\mathrm{S}$, Onoue S. Exploratory and regulatory assessments on photosafety of new drug entities. Curr Drug Saf 2012;7:140-8.

34. Nishida H, Hirota M, Seto Y, Suzuki G, Kato M, Kitagaki M, Sugiyama M, Kouzuki H, Onoue S. Non-animal photosafety screening for complex cosmetic ingredients with photochemical and photobiochemical assessment tools. Regul Toxicol Pharmacol 2015;72:578-85.

35. Haranosono Y, Kurata M, Sakaki H. Establishment of an in silico phototoxicity prediction method by combining descriptors related to photo-absorption and photo-reaction. J Toxicol Sci 2014;39:655-64.

36. Onoue S, Kawamura K, Igarashi N, Zhou Y, Fujikawa M, Yamada H, Tsuda Y, Seto Y, Yamada S. Reactive oxygen species assay-based risk assessment of drug induced phototoxicity: classification criteria and application to drug candidates. J Pharm Biomed Anal 2008;47:967-72.

37. Guideline IHT. ICH guideline M3 (R2) on nonclinical safety studies for the conduct of human clinical trials and marketing authorization for pharmaceuticals. ICH, European Medicines Agency, 2009, pp.1-26.

38. Matsumoto N, Akimoto A, Kawashima H, Kim S. Comparative study of skin phototoxicity with three drugs by an In vivo mouse model. J Toxicol Sci 2010;35:97-100.
39. Wagai N, Tawara K. Possible reasons for differences in phototoxic potential of a 5 quinolone antibacterial agents: generation of toxic oxygen. Free Radical Res Commun 1992;17:387-98.

40. Clewell HJ 3rd. Coupling of computer modeling with In vitro methodologies to reduce animal usage in toxicity testing. Toxicol Lett 1993;68:101-17.

41. Kandárová $\mathrm{H}$, Letašiová $\mathrm{S}$. Alternative methods in toxicology: Pre-validated and validated methods. Interdiscip Toxicol 2011;4:107-13.

42. Organization for Economic Cooperation and Development (OECD) Extended Expert Consultation Meeting on The In vitro 3T3 NRU Phototoxicity Test Guideline Proposal, Berlin, 30"' 31 ' October 2001, Secretariat's Final Summary Report, 15’ 11 March 2002, 2002.

43. Peters B. Holzhütter HG. In vitro phototoxicity testing: development and validation of a new concentration response analysis software and biostatistical analyses related to the use of various prediction models. Altern Lab Anim 2002;30:41532.

44. Pape WJ, Maurer T, Pfannenbecker U, Steiling W. The red blood cell phototoxicity test (photohaemolysis and haemoglobin oxidation): EU/COLIPA validation programme on phototoxicity (phase II). Altern Lab Anim 2001;29:145-62.

45. Yamamoto T, Tsurumaki Y, Takei M, Hosaka M, Oomori Y. In vitro method for prediction of the phototoxic potentials of fluoroquinolones. Toxicol In vitro 2001;15:721-7.

46. Sugiyama M, Itagaki H, Hariya T, Murakami N, Kato S. In vitro assays to predict phototoxicity of chemicals:(I) Red blood cell hemolysis assay. AATEX 1994;2:183-91.

47. Netzaff F, Lehr CM, Wertz PW, Schaefer UF. The human epidermis models EpiSkin (R), SkinEthic (R) and EpiDerm (R): An evaluation of morphology and their suitability for testing phototoxicity, irritancy, corrosivity, and substance transport. Eur J Pharm Biopharm 2002;60:167-78.

48. Boelsma E, Gibbs S, Faller C, Ponec M. Characterization and comparison of reconstructed skin models: morphological and immunohistochemical evaluation. Acta Derm Venereol 2000;80:82-8.

49. Ponec M, Boelsma E, Gibbs S, Mommaas M. Characterization of reconstructed skin models. Skin Pharmacol Appl Skin Physiol 2002;1;4-17.

50. Ponec M, Boelsma E, Weerheim A, Mulder A, Bouwstra M, Mommaas AM. Lipid and ultrastructural characterization of reconstructed skin models. Int J Pharm 2000;203:211-25.

51. Ponec M, Weerheim A, Kempenaar J, Mulder A, Gooris GS, Bouwstra J, Mommaas, AM. The formation of competent barrier lipids in reconstructed human epidermis requires the presence of vitamin C. J Invest Dermatol 1997;109:348-55.

52. Cannon CL, Neal PJ, Southee JA, Kubilus J, Klausner M. New epidermal model for dermal irritancy testing. Toxicol In vitro, 1994;8:889-91.

53. Netzlaff F, Lehr CM, Wertz PW, Schaefer UF. The human epidermis models EpiSkin, SkinEthic and EpiDerm: an evaluation of morphology and their suitability for testing phototoxicity, irritancy, corrosivity, and substance transport. Eur J Pharm Biopharm 2005;60:167-78. 
54. Jones P. In vitro phototoxicity assays. Editors: Chilcott RP, Price S. Skin Toxicology. John Wiley \& Sons, England. 2008, pp.169-183.

55. Ceridono M, Tellner P, Bauer D, Barroso J, Alépée N, Corvi R, De Smedt A, Fellows MD, Gibbs NK, Heisler E, Jacobs A, Jirova D, Jones D, Kandárová $\mathrm{H}$, Kasper P, Akunda JK, Krul C, Learn D, Liebsch M, Lynch AM, Muster W, Nakamura K, Nash JF, Pfannenbecker U, Phillips G, Robles C, Rogiers V, Van De Water F, Liminga UW, Vohr HW, Wattrelos O, Woods J, Zuang V, Kreysa J, Wilcox P. The 3T3 neutral red uptake phototoxicity test: Practical experience and implications for phototoxicity testing--the report of an ECVAM-EFPIA workshop. Regul Toxicol Pharmacol 2012;63:480-8.

56. Kejlová $\mathrm{K}$, Jirová $\mathrm{D}$, Bendová $\mathrm{H}$, Kandárová $\mathrm{H}$, Weidenhoffer Z, Kolárová H, Liebsch M. Phototoxicity of bergamot oil assessed by In vitro techniques in combination with human patch tests. Toxicol In vitro 2007;21:1298-1303.
57. Henry B, Foti C, Alsante K. Can light absorption and photostability data be used to assess the photosafety risks in patients for a new drug molecule? J Photochem Photobiol B 2009;96:57-62.

58. Onoue S, Seto Y, Kato M, Aoki Y, Kojo Y, Yamada S. Inhalable powder formulation of pirfenidone with reduced phototoxic risk for treatment of pulmonary fibrosis. Pharm Res 2013;30:1586-96.

59. Eskes C. Application of alternative methods in the regulatory assessment of chemical safety related to human skin corrosion $\&$ irritation current status and future prospects. Swiss Federal Office of Public Health - FOPH 2010.

60. Vinardell M.P. The use of non-animal alternatives in the safety evaluations of cosmetics ingredients by the Scientific Committee on Consumer Safety (SCCS). Regul Toxicol Pharmacol 2015;71:198-204. 